\title{
Raman Spectra and Analysis of Polynucleotides Containing Adenosine Residues*
}

\author{
Rosario Escobar \\ Departamento de Química Analítica, Facultad de Química, Universidad de \\ Sevilla, 41012-Sevilla, Spain \\ Pedro Carmona, $\uparrow$ Marina Molina and Aurora Lasagabaster \\ Instituto de Optica (CSIC), Serrano 121, 28006-Madrid, Spain
}

Seven salts of adenosine $5^{\prime}$-monophosphoric acid were synthesized and studied by Raman spectroscopy. The barium salt structure is known to adopt the $\mathbf{C}\left(4^{\prime}\right)$-exo-anti nucleoside conformation, whereas adenosine $5^{\prime}$-monophosphoric acid has the $\mathbf{C}\left(2^{\prime}\right)$-endo-anti nucleoside structure. The structures of the other compounds reported in this work are, as yet, unknown. However, their Raman spectra indicate through their phosphoester stretching bands that they adopt either the $\mathbf{C}\left(3^{\prime}\right)$-endo-anti or the $\mathbf{C}\left(2^{\prime}\right)$-endo-anti nucleoside conformations. It is shown that the 1200-1400 and 600-850 $\mathrm{cm}^{-1}$ regions provide some spectral features generated by the different nucleoside conformations, particularly $\mathbf{C}\left(2^{\prime}\right)$ endo-anti, $\mathbf{C}\left(3^{\prime}\right)$-endo-anti and $\mathrm{C}\left(4^{\prime}\right)$-exo-anti, as a result of vibrational coupling between the motions of ribofuranose and purine rings. These spectral features allow these different geometries to be characterized by this technique. A Raman spectroscopic analytical method is also described for the estimation of the percentages of adenosine residues in polynucleotides.

Keywords: Raman spectroscopy; nucleotides

\section{Introduction}

Structural studies of nucleic acids have proceeded at an accelerating pace in recent years due to important technical advances in synthesis, crystallography, and spectroscopic methods. Although X-ray crystallography suggests probable structures for nucleic acids in vivo, spectroscopic methods are required to study nucleic acids for which the crystalline structures have not yet been determined. Ideally, such methods should be capable of revealing fine structural details and should be applicable over a wide range of sampling conditions. These capabilities are shared in varying degrees by laser Raman and infrared spectroscopy. ${ }^{1}$ This suggests the usefulness of vibrational spectroscopy as a means of determining whether structures revealed in crystals are maintained upon transfer of the molecules to an aqueous medium.

Each nucleotide residue in a nucleic acid chain has a local structure, which may depend on the identities of neighbouring nucleotides. ${ }^{2}$ It has been shown that different nucleoside sugar puckers and glycosidic bond orientations may coexist in polyribonucleotides. ${ }^{3}$ In this situation, Raman spectroscopy permits the identification of several spectral bands with frequencies and intensities characteristic of each local nucleotide geometry; these bands are referred to as conformation markers.

* Presented at Euroanalysis VIII, Edinburgh, Scotland, UK, September 5-11, 1993.

t To whom correspondence should be addressed.
In this work, we report the analytical characterization of the $\mathrm{C}\left(2^{\prime}\right)$-endo-anti, $\mathrm{C}\left(3^{\prime}\right)$-endo-anti, and $\mathrm{C}\left(4^{\prime}\right)$-endo-anti nucleoside structures in ribonucleotide adenosine residues using Raman spectroscopy. The Raman spectra of the compounds described here, have never, to our knowledge, been studied. Finally, a Raman spectroscopic analytical method is described for the estimation of the percentages of adenosine residues in polyribonucleotides in aqueous solution.

\section{Experimental}

\section{Synthesis}

Magnesium adenosine $5^{\prime}$-monophosphate, $\mathrm{Mg}(\mathrm{AMP}) \cdot 6 \mathrm{H}_{2} \mathrm{O}$, and calcium adenosine $5^{\prime}$-monophosphate, $\mathrm{Ca}(\mathrm{AMP}) \cdot 2 \mathrm{H}_{2} \mathrm{O}$, were prepared as follows. Adenosine $5^{\prime}$-monophosphoric acid, $\mathrm{H}_{2}$ (AMP), was dissolved in water with slight heating, and suspensions of the respective hydroxides were added to obtain a $1: 1$ acid:hydroxide mole ratio. The resulting solutions were stirred at $50^{\circ} \mathrm{C}$ until they became transparent. Then the solutions were slowly evaporated to obtain crystals. Found: C, 24.59; N, 14.93; H, 4.14. Calc. for $\mathrm{Mg}$ (AMP) $6 \mathrm{H}_{2} \mathrm{O}: \mathrm{C}, 25.13 ; \mathrm{N}, 14.66 ; \mathrm{H}, 4.62 \%$. Found: $\mathrm{C}$, $29.34 ; \mathrm{N}, 16.88 ; \mathrm{H}, 3.60$. Calc. for $\mathrm{Ca}(\mathrm{AMP}) \cdot \mathrm{H}_{2} \mathrm{O}: \mathrm{C}, 28.51$; $\mathrm{N}, 16.62 ; \mathrm{H}, 3.82 \%$.

Strontium and barium salts, $\operatorname{Sr}\left(\right.$ AMP) $\cdot 2 \mathrm{H}_{2} \mathrm{O}$ and $\mathrm{Ba}(\mathrm{AMP}) \cdot 7 \mathrm{H}_{2} \mathrm{O}$, were prepared similarly by using mixed solutions of $2: 1$ acid: hydroxide mole ratio for the barium salt, and by adding a slight excess of acid for the strontium compound. Found: C, 25.16; N, 14.56; H, 3.17. Calc. for $\mathrm{Sr}(\mathrm{AMP}) \cdot 2 \mathrm{H}_{2} \mathrm{O}: \mathrm{C}, 25.60 ; \mathrm{N}, 14.92 ; \mathrm{H}, 3.62 \%$. Found: $\mathrm{C}$, $20.67 ; \mathrm{N}, 11.79 ; \mathrm{H}, 3.48$. Calc. for $\mathrm{Ba}(\mathrm{AMP}) \cdot 7 \mathrm{H}_{2} \mathrm{O}: \mathrm{C}, 19.73$; $\mathrm{N}, 11.50 ; \mathrm{H}, 4.28 \%$.

The potassium salt, $\mathrm{K}_{2}(\mathrm{AMP}) \cdot 5 \mathrm{H}_{2} \mathrm{O}$, was obtained by mixing acid and hydroxide solutions in a $1: 2$ acid : hydroxide mole ratio. The $\mathrm{pH}$ of the resulting solution was adjusted to 7.0 with $\mathrm{HCl}$. A precipitate appeared on addition of methanol-ethanol $(1+1 \mathrm{v} / \mathrm{v})$; the precipitate was filtered off under vacuum and dried at room temperature. Found: $\mathrm{C}, 23.80 ; \mathrm{N}$, $13.29 ; \mathrm{H}, 3.34$. Calc. for $\mathrm{K}_{2}$ (AMP) $5 \mathrm{H}_{2} \mathrm{O}: \mathrm{C}, 23.39 ; \mathrm{N}, 13.63$; $\mathrm{H}, 4.30 \%$.

The cadmium salt, $\mathrm{Cd}(\mathrm{AMP}) \cdot 2 \mathrm{H}_{2} \mathrm{O}$, was prepared by mixing equimolar solutions of adenosine 5 -monophosphoric acid and $\mathrm{Cd}\left(\mathrm{NO}_{3}\right)_{2} \cdot 4 \mathrm{H}_{2} \mathrm{O}$. The $\mathrm{pH}$ of the resulting solution was adjusted to 6.0 with $0.01 \mathrm{~mol} \mathrm{dm}^{-3} \mathrm{NaOH}$, and the solution was then heated at $50^{\circ} \mathrm{C}$ with stirring to obtain complete precipitation. Found: C, 26.14; N, 14.98; H, 3.04. Calc. for Cd(AMP) $2 \mathrm{H}_{2} \mathrm{O}: \mathrm{C}, 26.24 ; \mathrm{N}, 15.30 ; \mathrm{H}, 2.64 \%$. The zinc compound, $\mathrm{Zn}\left(\right.$ AMP) $\cdot 2 \mathrm{H}_{2} \mathrm{O}$, was obtained similarly using equimolar amounts of zinc oxide and $\mathrm{H}_{2}$ (AMP).

The $\mathrm{H}_{2}$ (AMP) used was acquired from Sigma. Its monohydrate was prepared through slow evaporation of an aqueous 
solution of the commercial product. Found: $\mathrm{C}, 32.71 ; \mathrm{N}$, 19.06; $\mathrm{H}, 4.11$. Calc. for $\mathrm{H}_{2}(\mathrm{AMP}) \cdot \mathrm{H}_{2} \mathrm{O}: \mathrm{C}, 32.87 ; \mathrm{N}, 19.17$; $\mathrm{H}, 4.38 \%$.

\section{Spectroscopy}

The Raman spectra were recorded with a Jobin-Yvon Ramanor Model U-1000 spectrometer coupled to photoncounting electronics. Signals were fed into a Tandon personal computer for storage, display, plotting, and processing. An argon ion laser, Spectra-Physics Model 164, was employed for excitation, using the $514.5 \mathrm{~nm}$ line. The spectral resolution was $3 \mathrm{~cm}^{-1}$ and the frequencies, calibrated with plasma lines from the laser, are reported within $\pm 1 \mathrm{~cm}^{-1}$. Samples were transferred to 1-2 mm i.d. capillaries and their spectra were obtained from the average of at least three scans.

The aim of the quantitative analysis was to evaluate adenosine residues that may be present in polyribonucleotide strands. For calibration, standard aqueous solutions containing both polyriboadenylic acid and potassium dihydrogenphosphate were prepared. The concentration of polyriboadenylic acid was expressed as moles of monomer of this biopolymer. The ratio of moles of polyriboadenylic acid to moles of dihydrogenphosphate ranged from 0.3 to 1.0 , the concentration of the polynucleotide being the same $(0.25$ mol $\mathrm{dm}^{-3}$ ) in all the solutions. To establish titration curves for the adenosine residues, it was necessary to take account of the fact that the frequency of the $724 \mathrm{~cm}^{-1}$ band used for this evaluation is, in practice, not dependent on the usual nucleoside structures in solution. 4

\section{Results and Discussion}

The $800-850 \mathrm{~cm}^{-1}$ range is conformation-sensitive, since it contains $\mathrm{P}-\mathrm{O5}^{\prime}$ stretching bands of the nucleotide backbone itself, which are directly affected by changes in skeletal geometry. This is probably caused by a coupling of the $\mathrm{vP}-\mathrm{O5}^{\prime}$ motion with the ribose vibration near $860 \mathrm{~cm}^{-1}$, which has ribose-ring breathing character. ${ }^{4}$ The crystal structure of adenosine $5^{\prime}$-monophosphoric acid, $\mathrm{H}_{2}$ (AMP), is known from $\mathrm{X}$-ray crystallographic studies ${ }^{5}$ to involve the $\mathrm{C}\left(2^{\prime}\right)$-endo-anti adenosine. This structural detail is reflected by the position of the phosphoester $v O-P$ band, which appears at $823 \mathrm{~cm}^{-1}$ (Fig. 1). It is well known that the phosphoester bands lying in the $820-845 \mathrm{~cm}^{-1}$ range are attributable to the $\mathrm{C}\left(2^{\prime}\right)$-endo-anti conformation, and the bands appearing in the $810-820 \mathrm{~cm}^{-1}$ interval result from the presence of the $\mathrm{C}\left(3^{\prime}\right)$-endo-anti

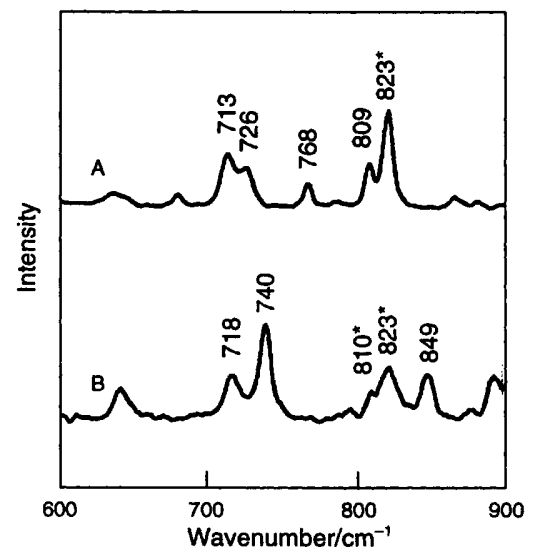

Fig. $1600-900 \mathrm{~cm}^{-1}$ Raman spectral region of $A, \mathrm{H}_{2}(\mathrm{AMP}) \cdot \mathrm{H}_{2} \mathrm{O}$, with $\mathrm{C}\left(2^{\prime}\right)$-endo-anti conformers, and $\mathrm{B}, \mathrm{K}_{2}(\mathrm{AMP}) \cdot 5 \mathrm{H}_{2} \mathrm{O}$ [the $v \mathrm{P}-\mathrm{O}$ bands at 823 and $810 \mathrm{~cm}^{-1}$ show that $\mathrm{K}_{2}$ (AMP) $\cdot 5 \mathrm{H}_{2} \mathrm{O}$ has $\mathrm{C}\left(2^{\prime}\right)$-endoanti and $\mathrm{C}\left(3^{\prime}\right)$-endo-anti conformers]. Marker bands are asterisked. adenosine ${ }^{6,7}$ Accordingly, we can assign the $823 \mathrm{~cm}^{-1}$ band of $\mathrm{H}_{2}$ (AMP) $\cdot \mathrm{H}_{2} \mathrm{O}$ crystals to the $\mathrm{C}\left(2^{\prime}\right)$-endo-anti conformation. As to the potassium salt, $\mathrm{K}_{2}(\mathrm{AMP}) \cdot 5 \mathrm{H}_{2} \mathrm{O}$, its crystal structure is not yet known, but there are two phosphoester bands at 810 and $823 \mathrm{~cm}^{-1}$ (Fig. 1) suggesting that the earlier mentioned nucleoside structures are present in this salt. This is confirmed by the profile of the $1290-1400 \mathrm{~cm}^{-1}$ region. Typically, there are three bands located in the 1295-1310, 1330-1350 and $1370-1395 \mathrm{~cm}^{-1}$ regions, as shown in the spectra of the compounds studied in this work. For the potassium salt, there are two bands in the $1330-1350 \mathrm{~cm}^{-1}$ region, at 1335 and 1344 $\mathrm{cm}^{-1}$ (Fig. 2). The $1335 \mathrm{~cm}^{-1}$ band is very close to that obtained for polyriboadenylic acid $\left(1337 \mathrm{~cm}^{-1}\right)$, where ribose adopts the $\mathrm{C}\left(3^{\prime}\right)$-endo pucker. By taking into account the presence of a vO-P phosphoester vibrational mode at 823 $\mathrm{cm}^{-1}$ (Fig. 1), we can attribute the band at $1344 \mathrm{~cm}^{-1}$ to the $\mathrm{C}\left(2^{\prime}\right)$-endo-anti conformation, which is also present in $\mathrm{K}_{2}$ (AMP) $\cdot 5 \mathrm{H}_{2} \mathrm{O}$ crystals. On this basis, the Raman line at $1346 \mathrm{~cm}^{-1}$ in the $\mathrm{H}_{2}$ (AMP) $\cdot \mathrm{H}_{2} \mathrm{O}$ spectrum can be correlated with the $\mathrm{C}\left(2^{\prime}\right)$-endo-anti structure revealed through $\mathrm{X}$ ray crystallography. ${ }^{5}$ Some workers 8 have prepared $\mathrm{H}_{2}$ (AMP) $\cdot \mathrm{H}_{2} \mathrm{O}$ from commercial adenosine $5^{\prime}$-phosphate, which was crystallized by slow evaporation of an aqueous solution adjusted to $\mathrm{pH} 2-3$ with a small amount of $\mathrm{HCl}$. These $\mathrm{H}_{2}$ (AMP) $\cdot \mathrm{H}_{2} \mathrm{O}$ crystals were observed to have monoclinic symmetry, and the molecules were described in terms of the $\mathrm{C}\left(3^{\prime}\right)$-endo-anti structure. Hence, the possibility that some $\mathrm{H}_{2}$ (AMP) $\cdot \mathrm{H}_{2} \mathrm{O}$ crystals with this nucleoside structure are also present in our sample appears to be supported by the presence of the phosphoester band at $809 \mathrm{~cm}^{-1}$ (Fig. 1). Therefore, it is probable that the strong Raman signal of this compound at $1320 \mathrm{~cm}^{-1}$ (Fig. 2) includes some contribution from the $\mathrm{C}\left(3^{\prime}\right)$ endo-anti structure.

The Raman spectra of magnesium, calcium and strontium salts show phosphoester bands between 820 and $830 \mathrm{~cm}^{-1}$; these are caused by the $\mathrm{C}\left(2^{\prime}\right)$-endo-anti conformation (Fig. 3 ). These salts also exhibit another band, which falls in the 1340$1350 \mathrm{~cm}^{-1}$ region (Fig. 4).

Another example of the coexistence of two different ribofuranose puckers is supplied by the cadmium salt (Fig. 5), for which the vO-P phosphoester region shows two bands at 816 and $828 \mathrm{~cm}^{-1}$, which are accompanied by another two bands at 1336 and $1349 \mathrm{~cm}^{-1}$ (Fig. 6).

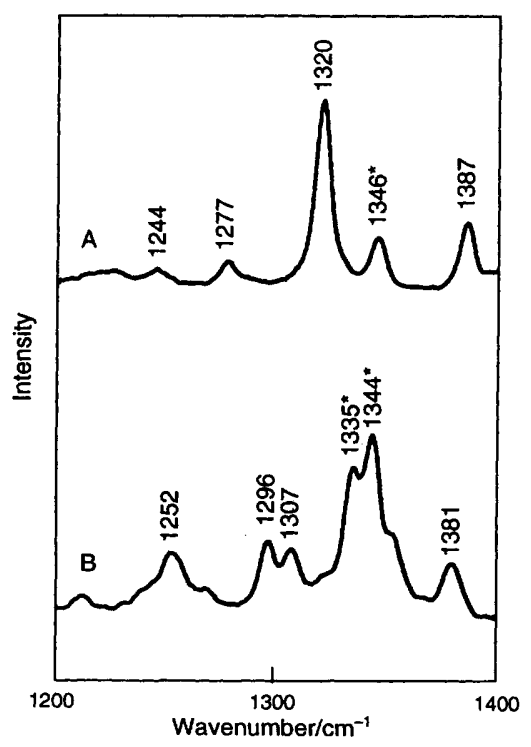

Fig. $21200-1400 \mathrm{~cm}^{-1}$ Raman spectral region of $A, H_{2}$ (AMP) and $\mathrm{B}, \mathrm{K}_{2}(\mathrm{AMP}) \cdot 5 \mathrm{H}_{2} \mathrm{O}$. Marker bands are asterisked. 
By considering the positions of the phosphoester stretching bands of these compounds we can state that whenever these bands fall in the $820-845 \mathrm{~cm}^{-1}$ range they are accompanied by another band in the interval between 1340 and $1350 \mathrm{~cm}^{-1}$. In addition, if the phosphoester band appears between 810 and $820 \mathrm{~cm}^{-1}$, another band appears in the $1330-1340 \mathrm{~cm}^{-1}$ range. This spectral correlation is reflected in Table 1 , which lists the frequencies of the vO-P phosphoester bands and those bands falling in the $1300-1400 \mathrm{~cm}^{-1}$ range. This spectral correlation appears to be similar to that established for some polynucleotide duplexes having $A$ and $B$ backbone structures. 1,9 In fact, the marker bands of these structures were found to be well separated, that is, the $A$ and $B$ polynucleotide backbones with the $\mathrm{C}\left(3^{\prime}\right)$-endo-anti and $\mathrm{C}\left(2^{\prime}\right)$-endo-anti conformations of the nucleoside repeat unit gave rise to marker bands near 1335 and $1345 \mathrm{~cm}^{-1}$, respectively. ${ }^{1,9}$ Different behaviour is displayed by the barium salt of adenosine 5 '-monophosphoric

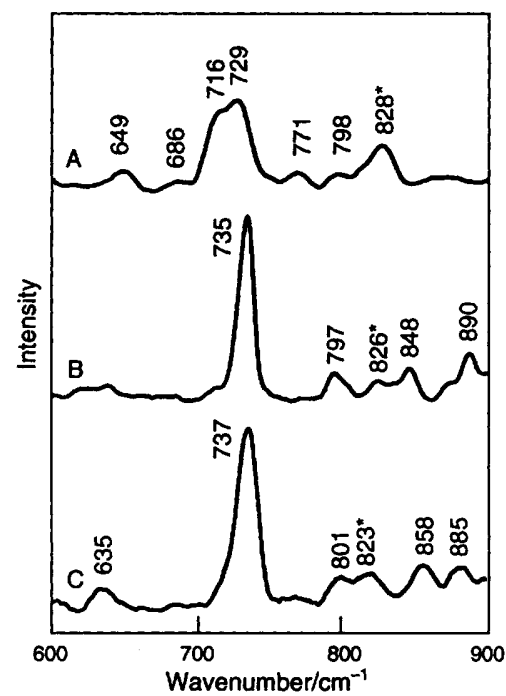

Fig. $3600-900 \mathrm{~cm}^{-1}$ Raman spectral region of $A, M g(A M P) \cdot 6 \mathrm{H}_{2} \mathrm{O}$, $B, \mathrm{Ca}(\mathrm{AMP}) \cdot 2 \mathrm{H}_{2} \mathrm{O}$, and $\mathrm{C}, \mathrm{Sr}(\mathrm{AMP}) \cdot 2 \mathrm{H}_{2} \mathrm{O}$. The frequencies of the marker bands (asterisked) indicate that these compounds have $\mathrm{C}\left(2^{\prime}\right)$ endo-anti conformers.

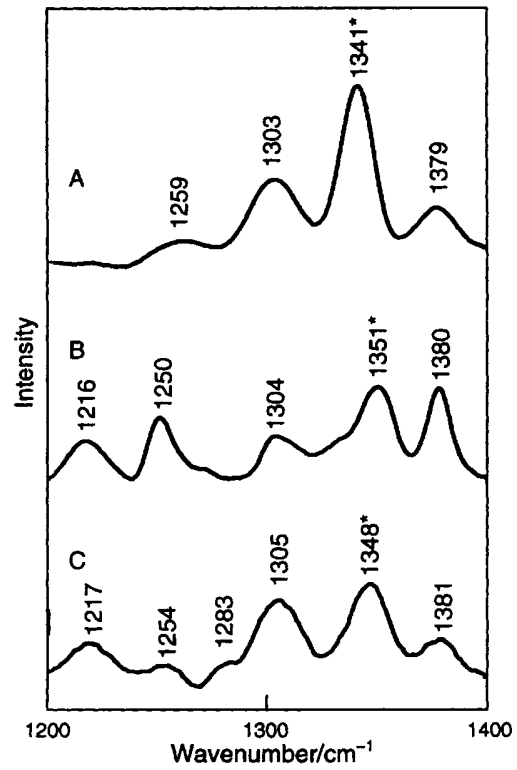

Fig. $41200-1400 \mathrm{~cm}^{-1}$ Raman spectral region of $\mathrm{A}$, $\mathrm{Mg}(\mathrm{AMP}) \cdot 6 \mathrm{H}_{2} \mathrm{O}, \mathrm{B}, \mathrm{Ca}(\mathrm{AMP}) \cdot 2 \mathrm{H}_{2} \mathrm{O}$, and $\mathrm{C}, \mathrm{Sr}(\mathrm{AMP}) \cdot 2 \mathrm{H}_{2} \mathrm{O}$. Marker bands are asterisked. acid, $\mathrm{Ba}(\mathrm{AMP}) \cdot 7 \mathrm{H}_{2} \mathrm{O}$, which is known through $\mathrm{X}$-ray studies to contain adenosine residues in the $\mathrm{C}\left(4^{\prime}\right)$-exo-anti conformation. ${ }^{10}$ Although for the majority of salts of $\mathrm{H}_{2}(\mathrm{AMP}) \cdot \mathrm{H}_{2} \mathrm{O}$, the band in the $1295-1310 \mathrm{~cm}^{-1}$ interval lies below $1307 \mathrm{~cm}^{-1}$, this band shifts to $1311 \mathrm{~cm}^{-1}$ in the barium salt. We suggest that the upshifting of this band could be used as a spectral feature to characterize this adenosine residue structure. That the $1300-1400 \mathrm{~cm}^{-1}$ range is sensitive to the nucleoside conformational structure, can be explained by taking account of the fact that some in-plane vibrational modes of the adenine base and $\delta \mathrm{CH}$ vibrations of ribose fall in this range. These modes of the nucleobase involve vibrations of imidazole and pyrimidine rings, which may be coupled with the $\delta \mathrm{CH}$ motions of ribose. 11



Fig. $5 \quad 600-900 \mathrm{~cm}^{-1}$ Raman spectral region of $\mathrm{A}, \mathrm{Ba}(\mathrm{AMP}) \cdot 7 \mathrm{H}_{2} \mathrm{O}$ with the $\mathrm{C}\left(4^{\prime}\right)$-exo-anti structure, $\mathrm{B}, \mathrm{Zn}(\mathrm{AMP}) \cdot 2 \mathrm{H}_{2} \mathrm{O}$, and $\mathrm{C}$, $\mathrm{Cd}(\mathrm{AMP}) \cdot 2 \mathrm{H}_{2} \mathrm{O}$. The asterisked frequencies indicate that the zinc salt has $\mathrm{C}\left(2^{\prime}\right)$-endo-anti conformers, and that the cadmium salt contains both $\mathrm{C}\left(2^{\prime}\right)$-endo-anti and $\mathrm{C}\left(3^{\prime}\right)$-endo-anti conformers.

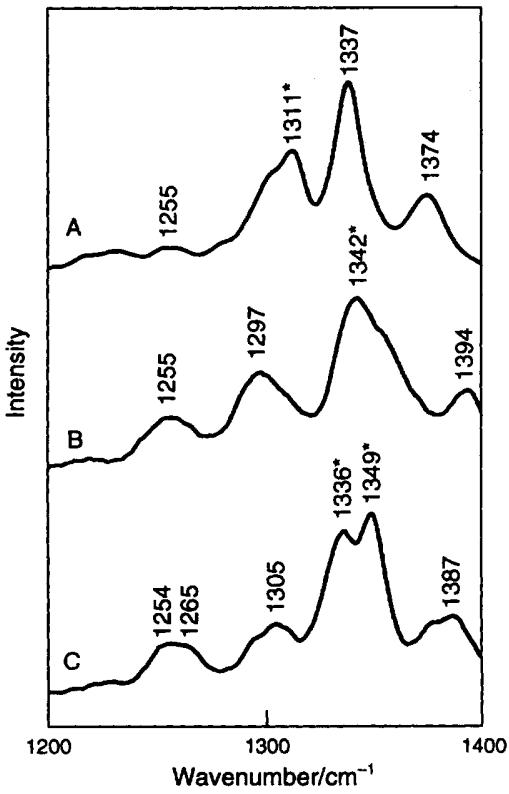

Fig. $61200-1400 \mathrm{~cm}^{-1}$ Raman spectral region of $\mathrm{A}$, $\mathrm{Ba}(\mathrm{AMP}) \cdot 7 \mathrm{H}_{2} \mathrm{O}, \mathrm{B}, \mathrm{Zn}(\mathrm{AMP}) \cdot 2 \mathrm{H}_{2} \mathrm{O}$, and $\mathrm{C}, \mathrm{Cd}(\mathrm{AMP}) \cdot 2 \mathrm{H}_{2} \mathrm{O}$. Marker bands are asterisked. 
The interest of using a non-destructive technique such as Raman spectroscopy for the titration of adenosine residues lies in being able to determine the percentage of adenosine residues in the polyribonucleotide chain. In this connection, the adenine band, which in practice appears around $724 \mathrm{~cm}^{-1}$ (Fig. 7), is not dependent on the nucleoside conformations detected to date in native polynucleotides in aqueous solution. ${ }^{1,4}$ Moreover, this band is well separated from the bands of guanine, cytosine, thymine, and uracil in the $700-800 \mathrm{~cm}^{-1}$ range. ${ }^{1}$ The titration curve, which is shown in Fig. 8, fits the

Table 1 Raman bands of compounds involving adenosine residues

\begin{tabular}{llll} 
Compound & $\begin{array}{l}\text { Adenosine } \\
\text { conformation }\end{array}$ & \multicolumn{2}{l}{ Frequency } \\
& $\mathrm{cm} \mathrm{cm}^{-1}$ \\
$\mathrm{H}_{2}$ (AMP) $\cdot \mathrm{H}_{2} \mathrm{O}$ & $\mathrm{C}\left(2^{\prime}\right)$-endo-anti & 823 & 1346 \\
$\mathrm{~K}_{2}$ (AMP) $5 \mathrm{H}_{2} \mathrm{O}$ & $\mathrm{C}\left(3^{\prime}\right)$-endo-anti & 810 & 1335 \\
& $\mathrm{C}\left(2^{\prime}\right)$-endo-anti & 823 & 1344 \\
$\mathrm{Mg}(\mathrm{AMP}) \cdot 6 \mathrm{H}_{2} \mathrm{O}$ & $\mathrm{C}\left(2^{\prime}\right)$-endo-anti & 828 & 1341 \\
$\mathrm{Ca}(\mathrm{AMP}) \cdot 2 \mathrm{H}_{2} \mathrm{O}$ & $\mathrm{C}\left(2^{\prime}\right)$-endo-anti & 826 & 1351 \\
$\mathrm{Sr}(\mathrm{AMP}) \cdot 2 \mathrm{H}_{2} \mathrm{O}$ & $\mathrm{C}\left(2^{\prime}\right)$-endo-anti & 823 & 1348 \\
$\mathrm{Ba}(\mathrm{AMP}) \cdot 7 \mathrm{H}_{2} \mathrm{O}$ & $\mathrm{C}\left(4^{\prime}\right)$-exo-anti & 801 & 1311 \\
$\mathrm{Zn}(\mathrm{AMP}) \cdot 2 \mathrm{H}_{2} \mathrm{O}$ & $\mathrm{C}\left(2^{\prime}\right)$-endo-anti & 829 & 1342 \\
$\mathrm{Cd}(\mathrm{AMP}) \cdot 2 \mathrm{H}_{2} \mathrm{O}$ & $\mathrm{C}\left(3^{\prime}\right)$-endo-anti & 816 & 1336 \\
& $\mathrm{C}\left(2^{\prime}\right)$-endo-anti & 828 & 1349
\end{tabular}

* The first value corresponds to the frequency of the vO-P phosphoester band; the second value is the frequency of the band falling in the $1300-1400 \mathrm{~cm}^{-1}$ range.

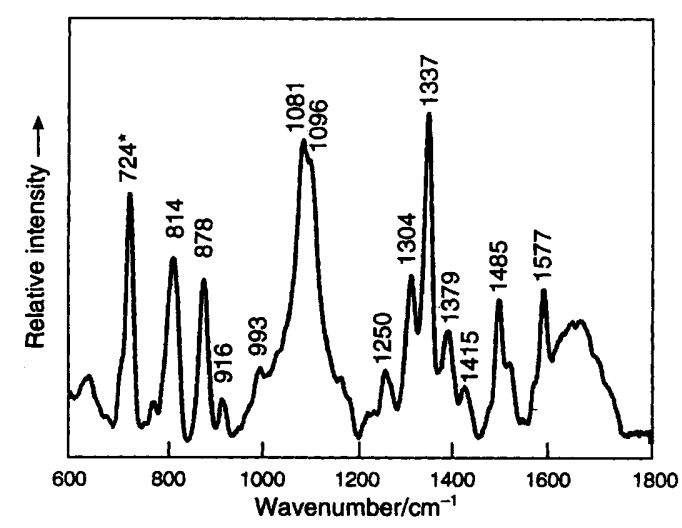

Fig. 7 Raman spectrum of an equimolar mixture $\left(0.25 \mathrm{~mol} \mathrm{dm}^{-3}\right)$ of potassium salt of polyriboadenylic acid and dihydrogenphosphate in aqueous solution. The marker band is asterisked.

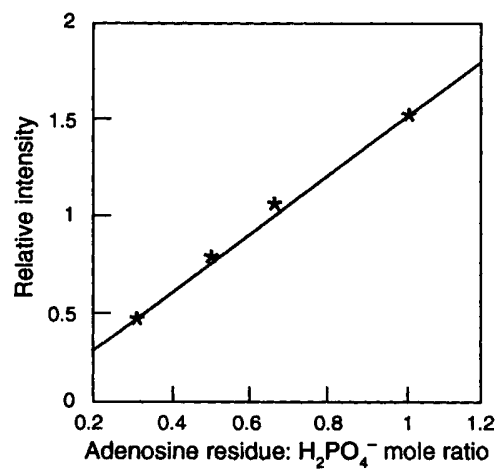

Fig. 8 Titration curve of the adenosine residue in polyribonucleotides. least-squares equation $I=1.53 R-0.012$, where $I$ is the intensity of the $724 \mathrm{~cm}^{-1}$ band relative to the band at $878 \mathrm{~cm}^{-1}$ due to dihydrogenphosphate used as internal standard, and $R$ the mole ratio of adenosine residue to internal standard. The least-squares correlation coefficient was found to be 0.99 , the precision for $I, 2 \%$. A question arises as to the presence of a small non-zero intercept (see Fig. 8); this can be explained as follows. The least-squares equation requires that $I$ is zero when $R$ is 0.007 ; that is, one cannot obtain a Raman signal at $724 \mathrm{~cm}^{-1}$ when the mole ratio of adenosine residues to internal standard is $0.7 \%$. The non-zero intercept is, hence, a result of the sensitivity of the technique, and the usual point dispersion obtained when titrating any compound.

In conclusion, we have reported for the first time the Raman spectra of adenosine $5^{\prime}$-monophosphoric acid and its $\mathrm{K}, \mathrm{Mg}$, $\mathrm{Ca}, \mathrm{Sr}, \mathrm{Ba}, \mathrm{Zn}$, and $\mathrm{Cd}$ salts, and the associated spectrumstructure correlation. The $\mathrm{C}\left(3^{\prime}\right)$-endo-anti, $\mathrm{C}\left(2^{\prime}\right)$-endo-anti, and $\mathrm{C}\left(4^{\prime}\right)$-exo-anti adenosine structures in polyribonucleotides can be characterized by Raman spectroscopy, mainly in the $1300-1400 \mathrm{~cm}^{-1}$ range. They are distinguishable from each other by having one band of medium-strong intensity in the $1330-1340$ and $1340-1350 \mathrm{~cm}^{-1}$ ranges, and one band near $1310 \mathrm{~cm}^{-1}$, respectively. A Raman spectroscopic analytical method was described for the estimation of the percentage rate of adenosine residues in polyribonucleotides. Fitting programs ${ }^{12}$ for the resolution of spectral profiles are being constructed in order to evaluate each of the above structures in ribonucleic acids.

Our thanks are due to the Dirección General de Investigación Científica y Técnica for financial support (PB90-0148).

\section{References}

1 Thomas, G. J., Jr., in Spectroscopy of Biological Systems, eds. Clark, R. J. H., and Hester, R. E., Wiley, Chichester, 1986, vol. 13, ch. 5, pp. 233-309.

2 Saenger, W., Principles of Nucleic Acid Structure, SpringerVerlag, New York, 1984, pp. 253-281.

3 Escobar, R., Carmona, P., and Molina, M., Fresenius' J. Anal. Chem., 1991, 340, 213.

4 Ridoux, J. P., Liquier, J., and Taillandier, E., Biochemistry, $1988,27,3874$

5 Neidle, S., Kuhlbrandt, W., and Achari, A., Acta Crystallogr., Sect. B, Struct. Crystallogr., 1976, 32, 1850.

6 Ghomi, M., Letellier, R., and Taillandier, E., Biopolymers, $1988,27,605$

7 Ghomi, M., Leteller, R., Liquier, J., and Taillandier, E., Int. J. Biochem., 1990, 22, 691.

8 Kraut, J., and Jensen, L. H., Acta Crystallogr., 1963, $16,79$.

9 Nishimura, Y., and Tsuboi, M., in Spectroscopy of Biological Systems, eds. Clark, R. J. H., and Hester, R. E., Wiley, Chichester, 1986, vol. 13, ch. 4, pp. 177-232.

10 Sternglanz, H., Subramanian, E., Lacey, J. C., and Bugg, C. E., Biochemistry, 1976, 15, 4797.

11 Dhaouadi, Z., Ghomi, M., Austin, J. C., Girling, R. B., Hester, R. E., Mojzes, P., Chinsky, L., Turpin, P. Y., Coulombeau, C., Jobic, H., and Tomkinson, J., J. Phys. Chem., 1993, 97, 1074

12 Raso, M. A., Tortajada, J., Escolar, D., and Acción, F., Comput. Chem., 1987, 11, 125.

Paper 3/05457H

Received September 13, 1993 Accepted October 28, 1993 